\title{
CARACTERIZAÇÃo dOS PRODUTOS LÍQUIDOS E DO CARVÃo DA PIRÓLISE DE SERRAGEM DE EUCALIPTO
}

Ayrton F. Martins*, Juraci Diniz, João A. Stahl e André de L. Cardoso

Departamento de Química da Universidade Federal de Santa Maria, Campus Camobi, 97105-900 Santa Maria - RS, Brasil

Recebido em 8/5/06; aceito em 20/9/06; publicado na web em 26/3/07

\begin{abstract}
CHARACTERIZATION OF LIQUID PRODUCTS AND CHAR FROM THE PYROLYSIS OF EUCALYPTUS SAWDUST. This study proposes the low temperature pyrolysis as an alternative conversion process for residual biomass and for obtaining gaseous, liquid and solid chemical feedstocks. Using a bench electrical pyrolysis oven, four product fractions from eucalyptus sawdust were obtained: a gaseous one, two liquid (aqueous and oily), and a solid residue (char). These products were characterized by different analytical methods. The liquid fractions showed themselves as potential sources for input chemicals. The residual char revealed appreciable adsorption capability. The process demonstrated good efficiency, generating at least two fractions of great industrial interest: bio oil and char.
\end{abstract}

Keywords: pyrolysis; characterization of products; eucalyptus sawdust.

\section{INTRODUÇÃO}

O aproveitamento de resíduos sólidos orgânicos é um tema que vem assumindo grande relevância na atualidade, em virtude das enormes quantidades geradas mundialmente e do indesejável impacto ambiental conseqüente. No Brasil, aproximadamente 0,62 Mt/a de serragem $^{1}$ são descartadas a céu aberto, provocando danos ao meio ambiente, principalmente a cursos d'água e mananciais. A serragem, pouco adequada à geração de energia, dado seu alto teor de umidade, também não pode ser aproveitada como fertilizante pelo seu baixo teor de nitrogênio, que dificulta a degradação microbiológica² ${ }^{2}$.

Neste contexto, a pirólise ${ }^{3}$ constitui uma atraente alternativa para aproveitamento de resíduos agroflorestais, com base na conversão termoquímica em atmosfera não oxidante, procedimento que contribui para a minimização do impacto ambiental e, também, para a geração adicional de produtos de apreciável valor econômico (insumos químicos e energéticos).

\section{PARTE EXPERIMENTAL}

\section{Materiais e métodos}

Os experimentos de pirólise de serragem de eucalipto (Eucalyptus grandis, madeireira local) foram conduzidos à baixa temperatura, em condições definidas, em reator de leito fixo (Forno bipartido tubular Maitec FT-1200/BI), em atmosfera inerte (fluxo mínimo de nitrogênio), segundo programa de temperatura desenvolvido para maximizar a produção de bioóleo e resíduo sólido. A seguir, efetuou-se a caracterização dos produtos de pirólise, compreendida pela análise dos produtos líquidos (fração aquosa e bioóleo) e do produto sólido (carvão).

Amostras de 10,0 g de serragem de eucalipto com diâmetro de partícula (dp) médio de $0,24 \mathrm{~mm}(0,18-0,30 \mathrm{~mm})$, pré-secas em estufa $\left(105{ }^{\circ} \mathrm{C}, 120 \mathrm{~min}\right)$ foram colocadas em barqueta de vidro $(\mathrm{d}=15,0 \mathrm{~mm} ; \mathrm{l}=250,0 \mathrm{~mm})$, que foi inserida em reator de vidro borossilicatado $(\mathrm{d}=30,0 \mathrm{~mm} ; \mathrm{l}=50,0 \mathrm{~mm})$. Este conjunto, por sua vez, foi colocado dentro de forno tubular, provido de termopar do tipo $\mathrm{S}$ e unidade digital de controle e programação da temperatura.

\footnotetext{
*e-mail: martins@quimica.ufsm.br
}

Um condensador foi adaptado à saída do reator para resfriamento (“quenching") e condensação dos produtos (Figura 1).

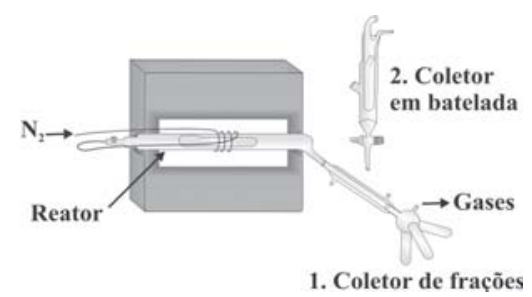

Figura 1. Sistema de conversão térmica à baixa temperatura

A biomassa foi aquecida em atmosfera inerte $\left(\mathrm{N}_{2}, 0,3 \mathrm{~L} \mathrm{~min}^{-1}\right)$,

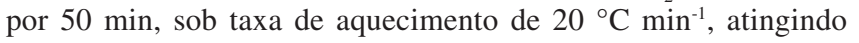
temperatura máxima final de $500{ }^{\circ} \mathrm{C}$; tempos de permanência de 5 $\min$ a $100,200,300,400$ e $500{ }^{\circ} \mathrm{C}$ foram empregados.

Obtiveram-se quatro frações por batelada: uma gasosa, duas líquidas, fração aquosa e bioóleo, e uma sólida, carvão.

Tabela 1. Faixas de temperaturas e frações obtidas no processo de conversão da serragem de eucalipto segundo programação estabelecida

\begin{tabular}{lcccc}
\hline Frações $\rightarrow$ & Gasosa & Aquosa & Oleosa & Sólida \\
\hline Faixa de Temperatura $\left({ }^{\circ} \mathrm{C}\right)$ & $25-500$ & $100-300$ & $300-500$ & $25-500$ \\
Rendimento $(\%)$ & 16 & 14 & 28 & 42 \\
\hline
\end{tabular}

\section{Equipamentos utilizados}

Para a análise elementar dos produtos líquidos e sólido utilizou-se equipamento Heraeus-Vario El.

Para determinação do teor de umidade utilizou-se método volumétrico baseado na aquametria com Titulador Karl Fischer Metrohm. As análises de absorção no infravermelho foram feitas pelo método de pastilha de $\mathrm{KBr}$ em espectrômetro Nicolet-Magna 500, auxiliado por acessório de Reflectância Total Atenuada Horizontal (HATR).

Dados referentes à difração de raios-X para o carvão foram 
obtidos em difratômetro Shimadzu Modelo XD, 7A, com tubo de cobre, $30 \mathrm{KV}$ e $30 \mathrm{~mA}$, varredura de $2-72^{\circ}$.

Para a identificação dos compostos constituintes das frações líquidas empregou-se cromatógrafo Varian Saturn 2100-T, com coluna DB (30,00 m x 0,25 mm x 0,25 $\mu \mathrm{m})$, acoplado a detector de espectrometria de massas.

A determinação da área superficial pelo método BET (Brunauer, Emmet \& Teller) ${ }^{4}$ foi feita em aparelho volumétrico, provido de bomba Turbomolecular Edward.

Para a análise de microscopia eletrônica por varredura (MEV) utilizou-se microscópio eletrônico Thermo Noran Jeol JSM-6360. Investigaram-se amostras de carvão obtidas em 400 e $500^{\circ} \mathrm{C}$, respectivamente.

A determinação do poder calorífico superior do bioóleo e do carvão foi feita em calorímetro VEB Vereinigte Babelsberger (exAlemanha Oriental).

A análise do carvão por espectroscopia de alta resolução em sólidos por ressonância magnética nuclear (EAR-RMN) foi feita com espectrômetro Varian INOVA 400 empregando-se MAS ("Magic Angle Spinning").

Como suporte instrumental para tanto, foram utilizados centrífuga Sigma 3K30, espectrofotômetros Femto 432 e Shimadzu MultiSpec-1501.

O índice de iodo 5 , a adsorção de azul de metileno ${ }^{6}$, o índice de fenazona ${ }^{7}$ e a adsorção de carboidratos ${ }^{8}$ foram determinados de acordo com a literatura para amostras do carvão de pirólise de serragem de eucalipto (CASE) e carvão ativo industrial (CAI). O poder de adsorção de corantes foi investigado com auxílio dos corantes ácido vermelho 1 (C.I. 18050) e amarelo erionyl 2G (C. I. 18.950)9

Para ativação do carvão da pirólise de serragem foi usado gerador de vapor de $2 \mathrm{~L}$, provido de fluxo de nitrogênio $\left(0,5 \mathrm{~L} \mathrm{~min}^{-1}\right)$ carreador do vapor d'água, sendo esta mistura pré-aquecida, como antes, o fluxo de $\mathrm{N}_{2}$ na pirólise injetando-se no reator a uma temperatura inicial de $100{ }^{\circ} \mathrm{C}$ e prosseguindo até a temperatura máxima de $850{ }^{\circ} \mathrm{C}$. A taxa de aquecimento foi mantida a $20{ }^{\circ} \mathrm{C} \min ^{-1} \mathrm{e}$ tempo de permanência, à temperatura máxima, de $120 \mathrm{~min}$ (tempo médio de ativação $160 \mathrm{~min}$ ).

\section{Descrição do método utilizado para teste de toxidade aguda do bioóleo}

Para os testes de toxidade aguda ${ }^{10}$ preparam-se soluções aquosas de bioóleo de serragem por meio de diluição a $5 \%$ em tween 80 , tamponadas com fosfato de potássio $0,5 \mathrm{~mol} \mathrm{~L}^{-1}$ e mantendo-se o pH em 7,3. Utilizaram-se camundongos albinos (Swiss) adultos, machos, pesando entre 30 e $40 \mathrm{~g}$, mantidos em sala com temperatura controlada $\left(22-25^{\circ} \mathrm{C}\right)$, com iluminação natural e alimentação e água ad libitum. Para determinação da $\mathrm{DL}_{50}$ (dose letal 50), os camundongos foram injetados pela via intraperitonial com uma dose $\left(10 \mathrm{~mL} \mathrm{~kg}^{-1}\right)$, de veículo ou bioóleo, nas concentrações 0,$070 ; 0,073$; 0,$182 ; 0,365 ; 0,639$ e $0,831 \mathrm{~g} \mathrm{~kg}^{-1}$ de peso corporal, e observados após $24 \mathrm{~h}$. Repetiu-se o procedimento injetando-se duas doses $\left(10 \mathrm{~mL} \mathrm{~kg}^{-1}\right)$, nas concentrações referidas em intervalos de $24 \mathrm{~h}$, sendo observados novamente após $24 \mathrm{~h}$.

\section{RESULTADOS}

\section{Caracterização das frações líquidas}

A análise elementar das frações líquidas (Tabela 2) demonstra um teor de oxigênio relativamente alto, característica dos insumos derivados diretamente da estrutura ligno-celulósica ${ }^{11}$, muito oxigenada. Observam-se baixos valores para enxofre e nitrogênio, com- parativamente, o que favorece a utilização de bioóleo em processos e sistemas para obtenção de energia (menor emissão de gases poluentes). A fração oleosa demonstrou-se solúvel em acetona, metanol e etanol.

Tabela 2. Propriedades das frações líquidas obtidas da pirólise de serragem de eucalipto

\begin{tabular}{lccc}
\hline Propriedades & & Fração aquosa & Bioóleo \\
\hline Análise elementar & $\mathrm{C}(\%)$ & 6,8 & 47,7 \\
& $\mathrm{H}(\%)$ & 11,4 & 7,7 \\
& $\mathrm{O}(\%)$ & 81,7 & 44,3 \\
& $\mathrm{~N}(\%)$ & - & $<0,1$ \\
& $\mathrm{~S}(\%)$ & - & $<0,1$ \\
Toxidade & 1 dose & - & $0,71(0,36-1,44)$ \\
$\mathrm{DL}_{50}\left(\mathrm{~g} \mathrm{~kg}^{-1}\right)$ & 2 doses & - & $0,93(0,63-1,37)$ \\
Teor de água $(\%)$ & - & - & 15,0 \\
Poder calorífico superior $\left(\mathrm{cal} \mathrm{g}^{-1}\right)$ & - & 4.013 \\
\hline
\end{tabular}

A identificação dos constituintes químicos da fração aquosa e do bioóleo através de GC-MS revelou substâncias de estruturas complexas, claramente derivadas da degradação química dos constituintes ligno-celulósicos da serragem de eucalipto.

A análise da fração aquosa (Figura 2) demonstra a presença de uma gama de compostos oxigenados, tais como ácidos carboxílicos, ésteres, éteres e cetonas. Ácidos carboxílicos e ésteres de cadeias longas (metil oleato, metil estearato, etc.) são derivados da pirólise de estruturas complexas (ceras e gorduras vegetais) que compõem a madeira de eucalipto. Substâncias como 1,1-dimetóxi heptano e 3,4-dimetilexano são provavelmente derivados da pirólise de óleos essenciais de eucalipto ${ }^{12}$ obtidos entre 200 e $300^{\circ} \mathrm{C}$. Compostos fenólicos com cadeias alquílicas, com 2 ou 3 carbonos, como 1-(3hidroxi-4-metóxifenil)-propanonona e 3,6-di-hidroxi-4-etóxifenilpropanonona, são formados em intervalo de temperatura de $100 \mathrm{a}$ $300{ }^{\circ} \mathrm{C}$ pela clivagem das ligações $\mathrm{C}-\mathrm{O}-\mathrm{C}$ que interligam as unidades de lignina ${ }^{13}$.

Observa-se a presença de outros compostos de elevado peso molecular, como ftalatos também formados pela clivagem simples das ligações que constituem os compostos originais complexos, além de compostos nitrogenados (2,4-dimetildifenilamina), confirmando a presença de nitrogênio detectada na análise elementar.

Certamente, há uma contaminação da fase aquosa com traços de bioóleo formado mesmo antes de $280{ }^{\circ} \mathrm{C}$.

A análise do bioóleo (Figura 2) comprova a natureza fenólica citada na literatura referente à ocorrência de compostos de baixo peso molecular (monômeros) derivados de lignina ${ }^{13,14}$. Temperaturas maiores levam à maior degradação dos constituintes da biomassa - hemicelulose, celulose $\mathrm{e}^{15-17}$ e lignina.

Entre os monômeros da lignina detectados destacam-se o seringol (2,6-dimetoxi-fenol), eugenol (2-metóxi-4-(2 propepil) fenol) e compostos fenólicos metóxi-substituídos (1,4-metóxi-fenol) derivados das reações primárias da lignina, além de outros compostos aromáticos substituídos, como 2-metóxi-4-propil-fenol, vanilina, 4-metil2-metoxi-fenol, etc. Verifica-se a presença de compostos complexos altamente oxigenados, derivados de prováveis reações radicalares secundárias ${ }^{13,14}$, tais como 1-(2,6-di-hidroxi-4-metóxifenil)-etanona e 1-(2,4,6-tri-hidroxi-3-(metilfenil)-1-butanona. Reações radicalares também são responsáveis pela formação de compostos de menor peso molecular, comprovadas pela presença de trimetóxi metano (fase aquosa) e 1,1,2-trimetoxi etano. Acetatos de dimetil hexanal são formados a partir da pirólise de terpenos, como citronelal, presentes entre os extrativos do eucalipto ${ }^{12}$. 
Identificaram-se compostos derivados da termodegradação de polissacarídeos (celulose e hemicelulose), com destaque para 2,5dimetóxitetra-hidrofurano, metil-2-furoato, tetra-hidro-2-furanometanol e compostos cíclicos identificados como etil ciclopetenolona, 3-metil-2-hidroxi-2-ciclopenten-1-ona, etc. Substâncias como 5-metil-3-metoxi-2-hexanona são prováveis produtos da degradação secundária de levoglicosano - o primeiro derivado da degradação da celulose ${ }^{15-17}$.

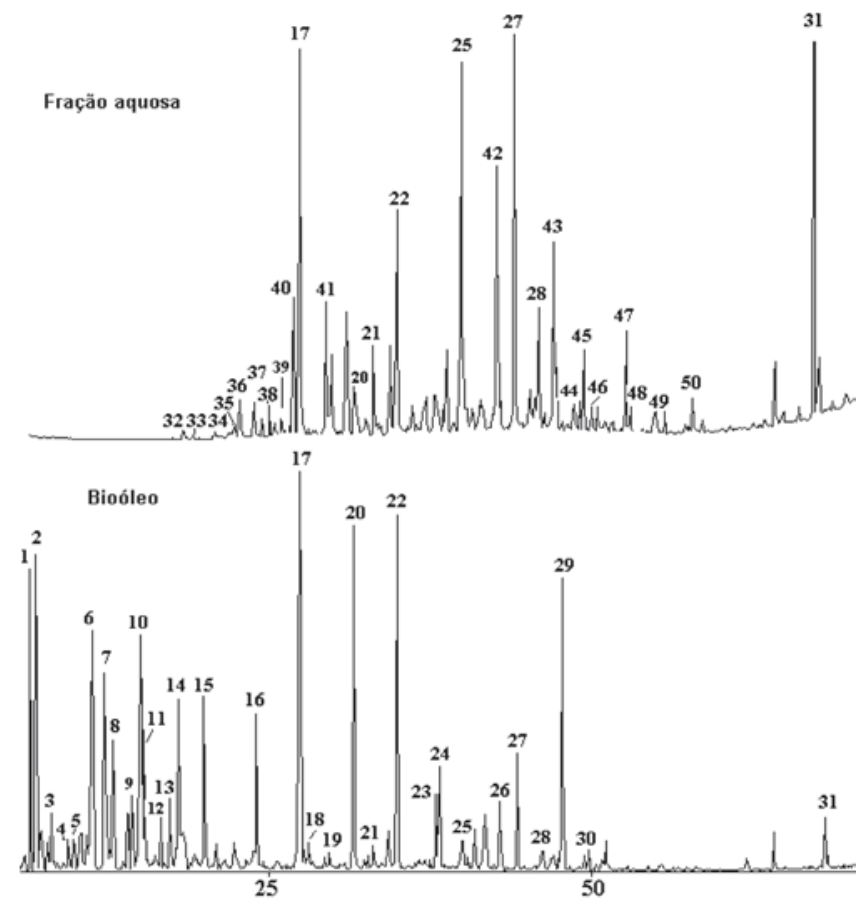

1. 2,5-dimetóxitetra-hidrofurano; 2. 2,3-dimetóxitetra-hidrofurano; 3. 1,1,2-trimetóxi etano; 4. 3-metil2-ciclopenten-1-ona; 5. metil-2-furoato; 6. tetra-hidro-2-furanometanol 7. acetato de 4,4-dimetil hexanal; 8. acetato de 4,5-dimetil hexanal; 9. etil ciclopentenolona 10. 1,4 metóxi fenol;11. 3-metil 2-hidroxi-2ciclopenten-1-ona; 12. 3-etil-2-hidroxi-2-ciclopenten-1-ona; 13. 2,3-dimetil pentanodiato; 14. 5-metil3-metoxi-2-hexanona; 15. 4-metil-2-metóxi fenol; 16. 4-etil-2-metoxi fenol; 17. 2,6-dimetoxi fenol; 18. 2-metóxi-4-(2-propenil) fenol; 19. 2-metóxi-4-propil fenol; 20. 1,2,3-trimetóxi benzeno; 21. 1-(4-hidroxi3-metóxifenil) etanona; 22. 1-(4-hidroxi-3-metóxifenil) etanona; 23. 2,6-dimetoxi-4-(2-propenil) fenol; 24. 4-etil difenil metano; 25. 4-hidroxi-3,5-dimetóxi benzaldeído; 26. 1-(4-hidroxi-3,5-dimetóxifenil) etanona; 27. 1-(2,4,6-tri-hidroxi-3-metilfenil)-1-butanona; 28. 1-(4-hidroxi-3,6-dimetóxifenil)-1-etanona; 29. diisobutil ftalato; 30. metil palmitato; 31. dietil-hexil ftalato; 32. trimetóxi metano; 33. 3,4-dimetilhexano; 34. 1-metil-2,2-dimetil butanodiato; 35. 2-metóxietil propanoato; 36. 3-metóxi-5-metil 2hexanona; 37. 1,1-dimetóxi heptano; 38. ácido 2-dimetil-3-etil butanóico; 39. Ácido 2-dimetil-3-metil butanóico; 40. 1,1-dimetóxi octano; 41. vanilina; 42. 1-(4-hidroxi-3-metóxifenil) etanona; 43. 2,4dimetildifenilamina; 44. diisobutil ftalato; 45. metil palmitato; 46. diisooctil ftalato; 47. metil 2-etilexil ftalato; 48. 1,1,1-trimetóxi etano; 49. metil oleato; 50. metil estearato.

Figura 2. Cromatograma de GC-MS obtido para as frações líquidas da pirólise de serragem de eucalipto

O espectro de infravermelho (Figura 3) obtido para o bioóleo demonstra estrutura predominante fenólica com bandas características de anéis aromáticos e grupos hidroxila, além da presença de grupos carbonila correspondentes às cetonas e ésteres e ligações $\mathrm{O}-\mathrm{C}$ dos grupos metoxil. Bandas largas em $3.370 \mathrm{~cm}^{-1}$ correspondem à deformação axial de $\mathrm{O}-\mathrm{H}$ do anel fenólico; banda média em 2.950 $\mathrm{cm}^{-1}$ corresponde à deformação axial $\mathrm{C}-\mathrm{H}$ de aromáticos acoplados à deformação axial da ligação $\mathrm{C}=\mathrm{O}$ de ésteres e cetonas. Observase, também, banda característica de deformação axial normal de $\mathrm{C}=\mathrm{O}$ de cetonas em $1.717 \mathrm{~cm}^{-1}$ e bandas correspondentes à deformação angular da ligação $\mathrm{C}=\mathrm{C}$ de aromáticos em 1.525 e $1.460 \mathrm{~cm}^{-}$
${ }^{1}$. A banda localizada em $1.360 \mathrm{~cm}^{-1}$ indica a vibração do anel siringílico, com contribuição do estiramento de $\mathrm{C}=\mathrm{O}$ e de estruturas condensadas. Em 1.230 e $1.100 \mathrm{~cm}^{-1}$ ocorrem bandas correspondentes à deformação axial simétrica $\mathrm{C}-\mathrm{O}-\mathrm{C}$ dos grupos metoxil (C-O anéis siringílicos) ${ }^{18}$.

O espectro de absorção no ultravioleta (Figura 4) de soluções alcoólicas de bioóleo apresenta bandas características de compostos fenólicos na faixa entre 210 - $260 \mathrm{~nm}$, além de bandas de menor intensidade em $282 \mathrm{~nm}$, correspondentes a grupos carbonila. Comprovou-se a presença de fenóis através da comparação entre espectros de UV de solução alcoólica de fenol $\left(20,0 \mathrm{mg} \mathrm{L}^{-1}\right)$ e solução alcoólica de bioóleo $\left(20,0 \mathrm{mg} \mathrm{L}^{-1}\right)$, em pH neutro. Por se tratar de mistura complexa formada por grande gama de compostos com variados tamanhos moleculares e grande diversidade de grupos químicos, a análise direta do bioóleo por RMN não permitiu nenhuma elucidação das estruturas constituintes.

O poder calorífico do bioóleo demonstrou valor médio de 4.013 kcal $\mathrm{kg}^{-1}$.

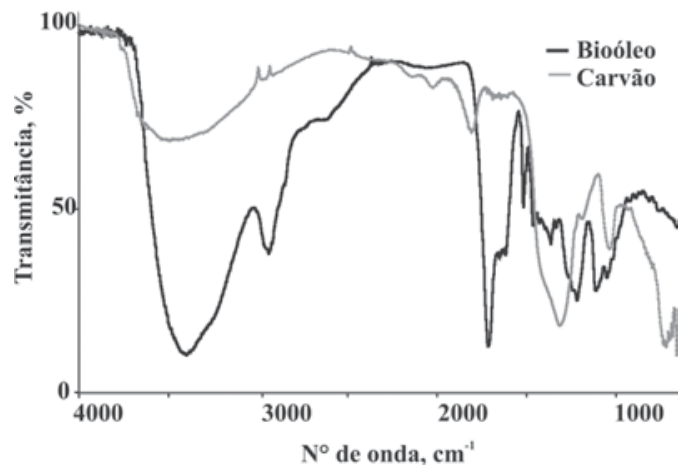

Figura 3. Espectro de infravermelho do bioóleo e carvão obtido da pirólise de serragem de eucalipto

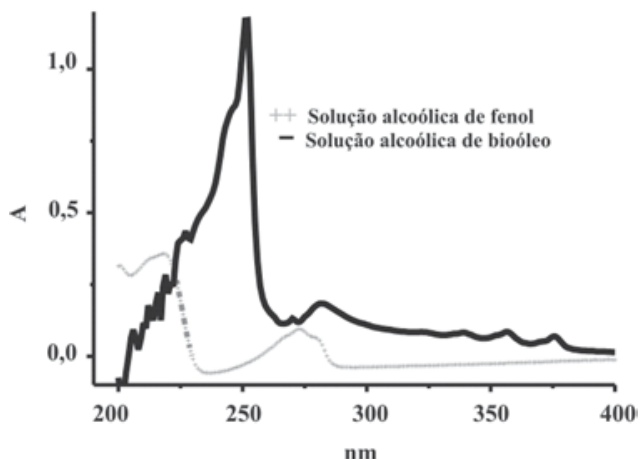

Figura 4. Espectros comparativos de absorção molecular por UV-vis de solução alcoólica de bioóleo e solução fenólica sob pH 7 e concentração de $20 \mathrm{mg} \mathrm{L}^{-1}$

Para os testes de toxidade, os valores $\mathrm{DL}_{50}$ e intervalos de confiança observados após exposição dos animais a uma e duas doses foram semelhantes (Tabela 2). Estes resultados indicam que o bioóleo, provavelmente, sofre excreção e/ou metabolização significativa no período de $24 \mathrm{~h}$ (vide parte experimental), pois drogas de metabolização e/ ou excreção lenta podem ter sua toxicidade potencializada após exposições repetidas em um curto intervalo de tempo ${ }^{19}$.

Segundo os critérios ${ }^{20}$ para a classificação de risco de toxicidade aguda, substâncias com $\mathrm{DL}_{50}$ oral para ratos menor que $25 \mathrm{mg} \mathrm{kg}^{-1}$, são classificadas como muito tóxicas; entre 25 e $200 \mathrm{mg} \mathrm{kg}^{-1}$ são tóxicas e, entre 200 e $2.000 \mathrm{mg} \mathrm{kg}^{-1}$ são classificadas como nocivas. Apesar deste critério não se referir exatamente às mesmas condições ex- 
perimentais empregadas no presente estudo, ele pode servir como base para situar o risco de toxicidade aguda associada ao bioóleo.

\section{Caracterização do carvão}

O carvão do processo pirolítico proposto demonstra alto teor de voláteis e baixos teores de carbono fixo, correspondendo a carvão de queima rápida, o que não é desejável para processos de obtenção de energia, embora os valores obtidos para o poder calorífico superior (Tabela 3) sejam próximos àqueles indicados pela literatura para carvão vegetal ${ }^{21}$. A análise por infravermelho (Figura 3) comprova estrutura constituída de hidrocarbonetos aromáticos polinucleados com absorções características em regiões de baixas freqüências. A banda mais importante é resultante da deformação angular fora do plano de C-H na região de 800-675 $\mathrm{cm}^{-1}$. O espectro demonstra banda larga de deformação axial C-H entre 3.100 e $3.000 \mathrm{~cm}^{-1}$; deformação angular da ligação $\mathrm{C}=\mathrm{C}$ de aromáticos em 1.600 e $1.440 \mathrm{~cm}^{-1}$ e deformação angular de metilenos terminais em $1.370 \mathrm{~cm}^{-1}$. Os dados obtidos nos testes de difração por raios-x (Figura 5) caracterizam estrutura amorfa com reduzida cristalinidade.

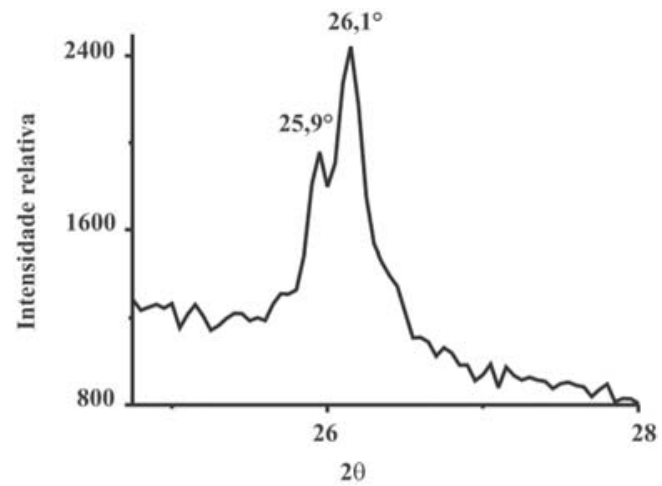

Figura 5. Difratograma de raios-x para o carvão de serragem de eucalipto

O espectro de EAR-RMN de ${ }^{13} \mathrm{C}$ (Figura 6) demonstra um pico principal, em torno de $126 \mathrm{ppm}$, corresponde a átomos de carbono em planos aromáticos com coordenação $\mathrm{sp}^{2}$, tipo grafite, o que é coerente com a estrutura turbostrática observada por difração de raios-X em materiais carbonizados.

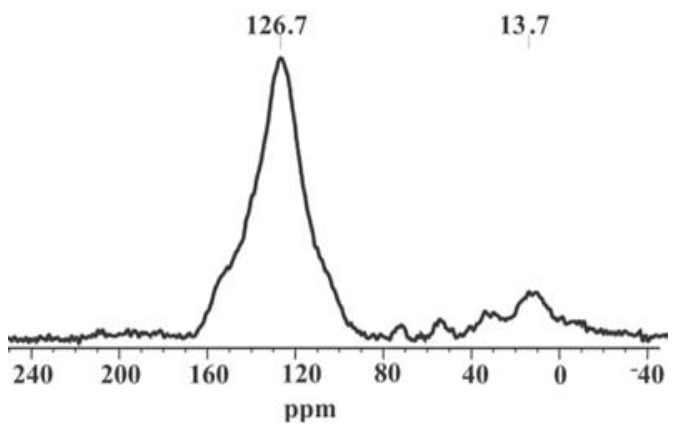

Figura 6. Espectro de ressonância magnética nuclear de alta resolução para sólidos (EAR-RMN) do carvão obtido da pirólise de serragem de eucalipto

A análise MEV (Figura 7) mostra a superfície porosa formada pela intensa eliminação de voláteis nas reações secundárias na estrutura da biomassa submetida a maiores tempos de retenção e a temperaturas superiores a $400{ }^{\circ} \mathrm{C}{ }^{22}$. Observa-se, nitidamente, o aumento do número de poros pela variação de temperatura de 400 a $500{ }^{\circ} \mathrm{C}$ e, também, o aumento do número de meso e macroporos em consequiência da ativação proposta.

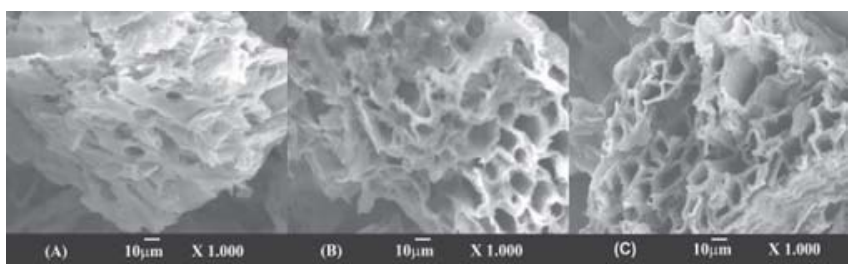

Figura 7. Microscopia eletrônica da partícula de carvão de serragem (aumento x 1000) da pirólise a (A) $400{ }^{\circ} \mathrm{C},(\mathrm{B}) 500{ }^{\circ} \mathrm{C} e(\mathrm{C})$ ativado à $850^{\circ} \mathrm{C}$

A análise por BET (Figura 8, Tabela 3) demonstra uma área superficial específica ${ }^{23}$ ainda inferior aos valores médios encontrados para carvão ativo comercial de madeira.

O carvão obtido da pirólise de serragem comporta-se como sólido macroporoso, pois a quantidade adsorvida tende a infinito quando $\mathrm{Pi} / \mathrm{P}_{0}$ tende a 1 , o que caracteriza uma adsorção em múltiplas camadas sobrepostas. A pequena histerese que ocorre entre $\mathrm{Pi} / \mathrm{P}_{0}$ de 0,6 a 0,9 justifica o aparecimento de mesoporos com diâmetro de $3 \mathrm{~nm}$ e, conseqüentemente, o volume de poros de

Tabela 3. Propriedades do carvão da pirólise de serragem de eucalipto.

\begin{tabular}{|c|c|c|c|c|}
\hline & Propriedades & $\mathrm{CASE}^{*}$ & $\mathrm{CAI} * *$ & CASE ativado \\
\hline \multirow[t]{4}{*}{ Análise imediata } & Voláteis $(\%)$ & 26 & $17,2^{21}$ & - \\
\hline & Carbono fixo $(\%)$ & 73,4 & $81,5^{21}$ & - \\
\hline & Umidade $(\%)$ & 4,4 & - & - \\
\hline & Densidade $\left(\mathrm{g} \mathrm{cm}^{-3}\right)$ & 0,1 & - & 0,1 \\
\hline \multirow[t]{8}{*}{ Testes de adsorção } & $\operatorname{BET}\left(\mathrm{m}^{2} \mathrm{~g}^{-1}\right)$ & 137 & 560 & 305 \\
\hline & Índice de iodo $\left(\mathrm{mg} \mathrm{g}^{-1}\right)$ & 179,0 & 409,0 & 370,0 \\
\hline & Índice de fenazona & 173,1 & 187,8 & - \\
\hline & Índice de azul de metileno $(\%)$ & 95,2 & 98,0 & - \\
\hline & Carboidratos $(\%)$ & 22,3 & 14,1 & - \\
\hline & Corante ácido vermelho $1(\%)$ & 27,3 & 49,1 & - \\
\hline & Corante amarelo erionyl 2G (\%) & 59,0 & 70,7 & - \\
\hline & Poder calorífico superior (cal g-1) & $5.913,5$ & $6.626,0^{21}$ & - \\
\hline
\end{tabular}

*CASE - carvão de pirólise de serragem de eucalipto; ${ }^{* *} \mathrm{CAI}$ - carvão ativo industrial 


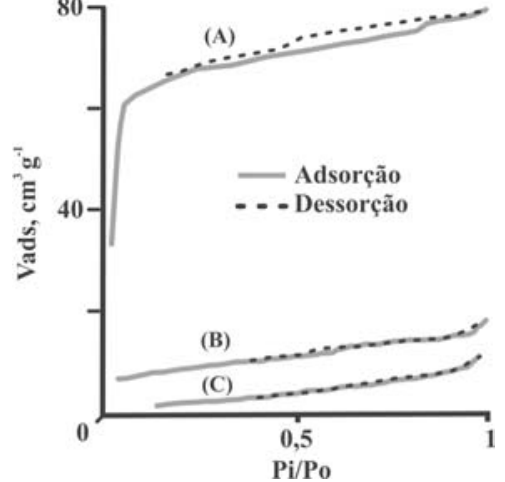

Figura 8. Histereses de adsorção e dessorção: (A) CAI; (B) CASE ativado e (C) $C A S E$

$0,20 \mathrm{~cm}^{3} \mathrm{~g}^{-1}$ (Figura 9). A baixa área superficial é justificada pela menor ocorrência de microporos.

Os resultados obtidos para o carvão ativado indicam modificação na estrutura deste sólido. No entanto, a quantidade de microporos ainda é insuficiente para modificar sensivelmente a isoterma. O comportamento da curva nas imediações de $\mathrm{Pi} / \mathrm{P}_{0}=1$ demonstra a existência de grande quantidade de macroporos. $\mathrm{O}$ formato da histerese também indica que os poros são constituídos de fendas entre camadas sobrepostas. A curva da distribuição de diâmetro de poros indica a existência de poros de diâmetros de 2,5 e 3,5 nm.

O índice de iodo (Tabela 3) obtido para carvão de serragem apresenta valor quatro vezes menor em relação ao mesmo índice obtido para carvão ativo comercial, observando-se, portanto, baixa microporosidade. Para o índice de fenazona (Tabela 3) observa-se similaridade de valores, indicando grau comparável de macroporosidade para os carvões analisados. Testes para azul de metileno (Tabela 3) demonstraram valores próximos para o carvão pirolítico e

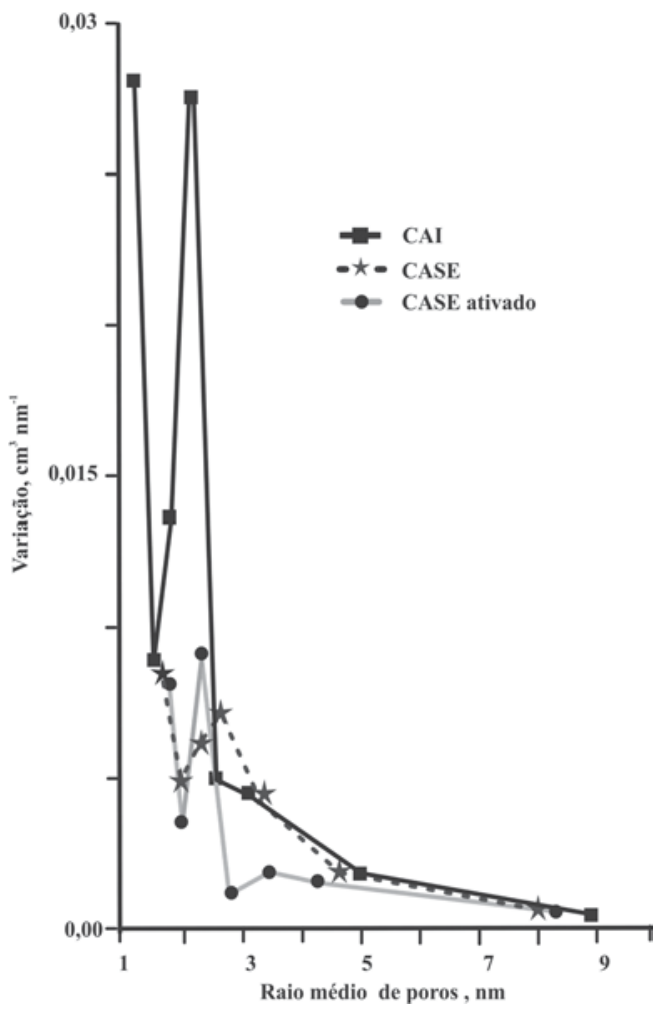

Figura 9. Distribuição do tamanho de poros do carvão de pirólise de serragem de eucalipto, do carvão de pirólise de serragem de eucalipto ativado e do carvão ativo industrial o carvão ativado comercial, indicando graus de mesoporosidade semelhantes, fato que se reflete nos testes de adsorção de corantes têxteis, ácido vermelho 1 e amarelo erionyl $2 \mathrm{G}$, cujos resultados são considerados próximos aos dos obtidos para carvão ativado. Entretanto, para o carvão de serragem ativado, observou-se um índice de iodo da ordem de $10 \%$ inferior ao do carvão ativo industrial.

A fração gasosa não foi objeto de estudo neste trabalho, sendo que sua composição é bastante conhecida ${ }^{24}$.

\section{CONCLUSÃO}

O processo desenvolvido, de conversão termoquímica à baixa temperatura, mostrou-se eficiente como processo alternativo para o aproveitamento de resíduo de biomassa - serragem de eucalipto - obtendo-se produtos líquidos (fração aquosa e bioóleo), sólido (carvão) e gasoso.

A fração aquosa obtida é constituída essencialmente por água (87\%) e compostos orgânicos diversos, com predominância de éteres, ésteres e ácidos carboxílicos. O bioóleo produzido pelo processo proposto é constituído por cerca de $20 \%$ de água e $80 \%$ de compostos orgânicos de natureza essencialmente aromática - derivados da decomposição da lignina. Apresenta apreciável poder calorífico. Pode, ainda, ser classificado como substância de risco quanto à toxicidade aguda.

O carvão residual, assim obtido, de estrutura amorfa, constitui um sólido de baixa porosidade, com predominância de meso e macroporosidade. Ainda que não ativado, demonstra apreciável capacidade de adsorção. Apresenta capacidade calorífica comparável à dos demais carvões de origem vegetal.

O processo de conversão à baixa temperatura de resíduos de biomassa gera, no mínimo, duas frações de grande interesse industrial: bioóleo, possível substituto de óleo combustível e aditivo de óleo diesel e fonte de insumos químicos; e, carvão, possível precursor de adsorvente industrial e combustível sólido.

Por último, o procedimento de ativação do carvão de pirólise de serragem de eucalipto, ainda que não otimizado, produziu carvão com propriedades adsorventes não muito distantes daquelas de um carvão ativo comercial.

\section{AGRADECIMENTOS}

Ao $\mathrm{CNPq}$ pelo apoio financeiro e aos colegas, E. B. Caramão e C. C. Moro, da UFRGS, E. A. Stadlbauer, da Universidade de Giessen, K. Albert, da Universidade de Tübingen, J. C. C. Freitas, da UFES e T. J. Bonagamba, da USP-SC, pelo auxílio analítico.

\section{REFERÊNCIAS}

1. http://www.radiobras.gov.br/ct/1997/materia_090597_12.htm, acessada em Maio 2004.

2. Budziak, C. R.; Maia, M. B. F.; Mangrich, A. S.; Quim. Nova 2004, 27, 399.

3. Martins, A. F.; Cardoso, A. L.; Stahl, J. A.; Diniz, J.; Bioresour. Technol. 2007, 98, 1095 .

4. Brunauer, S.; Emmett, P. H.; Teller, E.; J. Am. Chem. Soc.1938, 60, 309.

5. AWWW B604-74, American Water Works Association, Denver, Colorado, 1974.

6. Barton, S, S.; Carbon 1987, 25, 343

7. Farmacopéia Brasileira, $3^{\text {a }}$ ed., Organização Andrei Editora S.A: São Paulo, 1977.

8. Silva, R. N,: Monteiro, V. N.; Alcanfor, J. D. X.; Assis, E. M.; Asquieri, E. R.; Sci. Food Technol. 2003, 337.

9. Malik, P. K.; Dyes Pigm. 2003, 56, 239.

10. Litchfield Jr., J. T.; Wilcoxon, F. A.; J. Pharmacol. Exp. Ther. 1949, 96, 99.

11. Sjöström, E.; Wood chemistry: fundamentals and application, Academic Press: London, 1993.

12. Zrira, S. S.; Benjilali, B. B.; Fechtal, M. M.; Richard, H. H.; J. Essential Oil Res., 1992, 4, 259 
13. Amen-Che, C.; Pakdel, H.; Roy, C.; Biorsour Technol. 2001, 79, 277.

14. Dermibas, A.; Energy Conversion \& Management 2000, 41, 633.

15. Shafizadeh, F.; J. Anal. Appl. Pyrolysis 1982, 3, 283.

16. Piskorz, J.; Radlein, D.; Scott, D. S.; J. Anal. Appl. Pyrolysis 1996, 9, 121.

17. Scott, D. S.; Majerski, P.; Piskorz, J.; Radlein, D.; J. Anal. Appl. Pyrolysis 1999, 51, 23.

18. Özbay, N.; Pütün, A. E.; Uzun, B. B.; Pütün, E.; Renewable Energy 2001, 24, 615 .

19. Eaton, D. L.; Klaassen, C. D.; Principles of toxicology, $5^{\text {th }}$ ed., Mc Graw Hill: New York, 1995.
20. Barros, S. B. M.; Davino, S. C.; Avaliação da toxicidade, $2^{\mathrm{a}}$ ed., Atheneu: São Paulo, 2003.

21. Pereira, J. C. D.; Sturion, J. A.; Higa, A. R.; Higa, R. C. V.; Shimizu, J. Y.; Embrapa Florestas 2000, 38, 113.

22. Sharma, R. K.; Wooten, J. B.; Baliga, V. L.; Lin, X.; Chan, W. G.; Hajaligol, M. R.; Fuel 2001, 69, 112

23. Teixeira, V. G.; Coutinho, F. M. B.; Gomes, A. S.; Quim. Nova 2001, 24, 808.

24. Bridwater, A. V.; Peacocke, G. V. C.; Renew. and Sustain. Energy Reviews 2000, 4,1 